\title{
Intra-Soil Pulse Continuum-Discrete Moistening for Soil and Water Preservation
}

\author{
Batukaev A. A. \\ Chechen State University \\ Grozny, Russia \\ Complex Scientific Research Institute named after H. I. \\ Ibrahimov \\ Grozny, Russia \\ batukaevmalik@mail.ru \\ Rykhlik A. E. \\ The Institute of Soil Fertility of the South of Russia \\ Persianovka, Russia \\ tyoma-4444@yandex.ru
}

\author{
Kalinichenko V. P. \\ The Institute of Soil Fertility of the South of Russia \\ Persianovka, Russia \\ kalinitch@mail.ru
}

\author{
Batukaev A. A \\ The Agrotechnological Institute \\ Chechen State University \\ Grozny, Russia \\ batukaev_abuzar@mail.ru
}

\author{
Palaeva D. O. \\ The Agrotechnological Institute \\ Chechen State University \\ Grozny, Russia \\ dinna85@mail.ru
}

\begin{abstract}
-outdated technologies prevent the civilization from its development in the context of globalization. There is a preventing factor to apply the nature-resembling technologies that is a generally accepted simulation frontal gravity continuumisotropic paradigm of irrigation and drainage, which causes soil destruction and loss of fresh water. The work presents the results of a model experiment carried out in the framework of an innovative scientific and technical approach known as Biogeosystem Technique applied for the empirical demonstration of soil and water conservation opportunities provided by the intra-soil pulse continuum-discrete moisture paradigm are presented. The model system is a vegetative plastic transparent cylinder $20 \mathrm{~cm}$ high with a diameter of $5 \mathrm{~cm}$ having the ordinary chernozem soil inside. This sample soil was previously grated and poured as a layer of $0-30 \mathrm{~cm}$, with compaction approximate to the natural structure and density of soil. Then we simulated pulse continuum-discrete water flow inside the soil using the syringe of $20 \mathrm{ml}$ and the medical spinal needle with a length of $12 \mathrm{~cm}$. The experiment was carried out at the initial stage of spring-planted barley under natural insolation. We performed a surface irrigation, sprinkling, drip irrigation, and a new intra-soil pulse continuum-discrete method of soil moistening. After surface irrigation, sprinkling, drip irrigation we observed water seepage through the soil in the amount of 30-50\% of the given volume. After watering, we observed total subsidence of the surface, as well as the formation of crust on it. With the drip irrigation, there was also the surface subsidence and crust formation, but the processes were local taking place directly under the dropper. With pulsed intra-soil continuum-discrete moistening, the soil surface preserved its form as it had after filling the experimental model with soil, as the crust is not formed. The model system produced better developed barley plants with a new method of
\end{abstract}

moistening, and the water consumption was 1.5-2.5 times less than with the standard methods of watering plants.

Keywords-moistening, modeling, intra-soil pulse continuumdiscrete moistening

\section{INTRODUCTION}

The development of modern civilization in the context of globalization is focused on overcoming conflicts, separatist and extremist manifestations, ethnic and religious confrontation, and the transition to sustainable development and cooperation. In this way, there exists the priority of the modern economy - production and consumption. However, this priority by itself is able to provide presupposes unlimited possibilities of the Earth's ecosphere for the achievements of modern civilization, that underlies the contradictions of globalization that is the opposition of technology and the biosphere. Therefore, it is necessary not only to engage in consumption, but also to ensure the possibility of assonance of co-evolution of civilization and the biosphere, to develop an appropriate policy of social behaviour management in the environment (Gordeeva, 2017).

Modern technologies are based on the exploitation of the ecosphere, simulating fragments of natural phenomena for the utilitarian purposes of production. Therefore, as it was declared by the President of the Russian Federation V. V. Putin at the UN Assampley, there is an urgent purpose of the synthesis of the technologies that are non-contradictive to the ecosphere and environmentally-friendly. The thesis of the 
nature-resembling technologies is used in scientific literature (see the references to the research), but now it means only to copy or to imitate the nature. Meanwhile, the way of copying nature in the context of limited resources of the Earth and increasing technical possibilities of resource exploitation within the framework of outdated technologies of the industrial era not only leads to an avalanche-like increase in costs, but also increases the confrontation in society. First of all, people get less of the consumption preferences, and more of the ecosphere degradation, in which it is becoming less protected from natural and social disasters. Instead of harmony and cooperation, the modern economy leads to social conflicts.

To implement the thesis of natural technologies, we have proposed the biogeosystem technique providing transcendental technical solutions and technologies for controlling the biogeochemical cycle of substances in the gaseous, liquid, and solid phases. It also contributes to the safety of the ecosphere recycling of matter in soils, to the growth of food, to the effective solutions of industrial and environmental problems of the noosphere in a single technological cycle. On the basis of biogeosystem technique, it is possible to ensure harmonious development, and thus to overcome ethnic and religious conflict in the modern world

\section{MethodS AND MATERIALS}

To create a model system we used plastic transparent cylinders with a height of $20 \mathrm{~cm}$ and a diameter of $5 \mathrm{~cm}$. The ordinary chernozem soil was previously grated and poured as a layer of $0-30 \mathrm{~cm}$. To simulate discrete irrigation, a $20 \mathrm{ml}$ medical syringe and a $12 \mathrm{~cm}$ medical spinal needle were used. The physical volume for the repetition of the experiment is the container: with the diameter of $50 \mathrm{~mm}$ and the height of 200 $\mathrm{mm}$.

The method of creating a model system is filling the soil with compaction in the process of filling the vegetation vessel to a state approximate to the natural composition and density.

The method of creating a model of agrophytocenosis includes the preliminary germination of grain seeds on a wet porous substrate in order to ensure germination, the rejection of seeds with low germination in order to neutralize the starting conditions for the development of individual plants. Sprouted seeds were placed in the soil of the model container manually to a depth of $2 \mathrm{~cm}$.

The culture is barley.

The method of water supply is periodic or constant, and it is in accordance with the method of watering.

We simulated standard methods of watering: surface method (or irrigation), dripping method, and intra-soil pulse continuum-discrete method of moistening.

The standard methods of watering, such as surface method, dripping, and sprinkling, are functionally identical in relation to the soil, since all provide water delivery to the soil surface, after which the water seeps arbitrarily deep into the soil. The result of this is that, for example, at the estimated wet soil layer of $60 \mathrm{~cm}$, the water that goes through the depth of $1 \mathrm{~cm}$ of soil is 60 times more than it is necessary to moisten this layer. For this reason, there is an intensive destruction of the soil.

The subsurface irrigation method was not considered due to the fact that its negative environmental impact becomes obvious from its name. It is necessary to create an artificial groundwater level for its implementation. This is unacceptable in terms of saving water as a globally limited resource.

When simulating surface watering (sprinkling), two variants of the irrigation norm were used: standard watering rate, reduced watering rate.

When simulating dripping, we applied both variants of water supply intensity used according to the criterion of equal volume of supply: standard watering rate, reduced watering rate.

The intra-soil pulse continuum-discrete method of irrigation was simulated. We applied both variants: the dose of watering in the amount of reduced rate with the application of the imitation of surface watering, the minimum dose of watering. The method of water supply is a periodic dispersed injection of water deep into the soil in the process of removing the needle. In average, every day watering (in the evening) comes with $10 \mathrm{ml}$ of water for one time: 5 weeks 35 days 350 $\mathrm{ml}$, total layer $17.5 \mathrm{~cm}$. The water supply is considered in detail below according to the experiment options.

Experiment options:

1 Without watering (standard).

2 The imitation of the traditional method of watering. The watering norm $200 \mathrm{~m} 3 / \mathrm{ha} 20 \mathrm{~mm}, 2 \mathrm{~cm}$ (volume $39,2 \mathrm{ml} /$ capacity). Total for the experiment (an average intensity per day): week $1-15 \mathrm{ml} /$ day, $105 / 20=5 \mathrm{~cm}$; week $2-420 \mathrm{ml} /$ day, $420 / 20=21 \mathrm{~cm}$; from the 5th week $25 \mathrm{ml} /$ day, $175 / 20=8.5 \mathrm{~cm}$, total water layer 34.5 $\mathrm{cm}$.

3 The imitation of the traditional method of watering. The watering norm $133 \mathrm{~m} 3 / \mathrm{ha} 13.3 \mathrm{~mm}, 1.33 \mathrm{~cm}$ (volume 19,6 ml/capacity). Total for the experiment (an average intensity per day): week $1-10 \mathrm{ml} /$ day, $70 / 20=3.5 \mathrm{~cm}$; week $2-415 \mathrm{ml} /$ day, $315 / 20=15.8 \mathrm{~cm}$; from the 5 th week $20 \mathrm{ml} /$ day, $140 / 20=7 \mathrm{~cm}$, total water layer $26.3 \mathrm{~cm}$

4 Imitation of dripping. The intensity of the water supply is $10 \mathrm{ml}$ per day, with the 5 th week $20 \mathrm{ml}$ per day. The total amount for the experiment $420 \mathrm{ml}$, only the layer of water 21 see The intensity of $12-15 \mathrm{drop} / \mathrm{min}$, the duration of the water supply according to the daily dose. The diameter of the moisture circuit on the surface is not more than $1.5 \mathrm{~cm}$

5 Imitation of limited dripping. The intensity of the water supply is $5 \mathrm{ml}$ per day, with the 5 th week $10 \mathrm{ml}$ per day. The total amount for the experiment $210 \mathrm{ml}$, the total layer of water $10.5 \mathrm{~cm}$ The intensity of 12-15 drop/ min, the duration of the water supply according to the daily dose. The diameter of the moisture circuit on the surface is not more than $1.5 \mathrm{~cm}$. 
6 Intra-surface discrete watering. The depth of moistening with a syringe is $4-20 \mathrm{~cm}$ evenly along the height of the container. One watering volume of $5 \mathrm{ml} /$ capacity, starting from the 4 th week $10 \mathrm{ml}$. The total for the experiment is a layer of water of $16.2 \mathrm{~cm}$

7 Intra-surface discrete minimal watering. The depth of moistening with a syringe is $4-20 \mathrm{~cm}$ evenly along the height of the container. One watering volume of $3 \mathrm{ml} /$ capacity, starting from the 4th week $5 \mathrm{ml}$. Total for the experiment is a layer of water of $6.7 \mathrm{~cm}$

The experiment options are presented below in Table 1.

The imitation of the traditional method of watering was carried out according to the standard - the beginning of watering with soil moisture of 0.7 minimum moisture-holding capacity.
The imitation of the traditional limited method of watering was carried out in the same period as the imitation of the traditional method of watering.

Dripping - the regulation of water supply intensity according to the volume of supply of the traditional method of watering or, respectively, the traditional limited method of watering

Intra-surface discrete watering was carried out daily.

The microclimate - natural for the initial stage of organogenesis of spring barley.

Insolation of soil and plants in the experiment is natural.

Soil condition was determined visually and organoleptically.

The experiment was performed in 4 repetitions.

Statistical data processing-Excel Microsoft-Office 2010.

TABLE 1 THE RESULTS OF MODEL EXPERIMENT

\begin{tabular}{|c|c|c|c|c|c|}
\hline Option & $\begin{array}{l}\text { Method of soil } \\
\text { moistening }\end{array}$ & $\begin{array}{l}\text { Time of completion } \\
\text { week } 1 \text {. Dose of } \\
\text { moistening, ml. } \\
\text { Comments }\end{array}$ & $\begin{array}{c}\text { The time of } \\
\text { completion of } 2-4 \\
\text { weeks. } \\
\text { Dose of moistening, } \\
\text { ml. Comments } \\
\end{array}$ & $\begin{array}{l}\text { The period started from } \\
\text { the 5th week } \\
\text { Dose of moistening, ml. } \\
\text { Comments }\end{array}$ & $\begin{array}{l}\text { The comments on the state of plants } \\
\text { and soil during the experiment and } \\
\text { upon its completion }\end{array}$ \\
\hline 1 & Monitoring & $\begin{array}{c}10 \\
\text { simulation of a } \\
\text { medium dry year }\end{array}$ & No irrigation & No irrigation & The plant dies \\
\hline 2 & Traditional & 15 & 20 & 25 & $\begin{array}{l}\text { Water is retained on the soil surface. } \\
\text { High level of soil compaction when } \\
\text { watering. } \\
\text { The appearance of cracks in the soil } \\
\text { resulting from watering }\end{array}$ \\
\hline 3 & $\begin{array}{l}\text { Traditional } \\
\text { abridged }\end{array}$ & 10 & 15 & 20 & $\begin{array}{l}\text { Soil compaction, there are small cracks } \\
\text { on the soil surface }\end{array}$ \\
\hline 4 & Drop method & 10 & 10 & 20 & $\begin{array}{l}\text { Higher level of soil compaction than in } \\
\text { the option "Limited Dripping" }\end{array}$ \\
\hline 5 & Limited Dripping & 5 & 5 & 10 & $\begin{array}{l}\text { There is a centre of compaction under the } \\
\text { dropper in the soil }\end{array}$ \\
\hline 6 & $\begin{array}{c}\text { Intra-soil pulse } \\
\text { continuum-discrete } \\
\text { watering } \\
\end{array}$ & 5 & 10 & 10 & $\begin{array}{c}\text { Plants visually look good, but inferior to } \\
\text { the option of "Traditional watering" in } \\
\text { height by an average of } 2.3 \mathrm{~cm}\end{array}$ \\
\hline 7 & $\begin{array}{l}\text { Intra-soil pulse } \\
\text { continuum-discrete } \\
\text { watering with a } \\
\text { reduced dose }\end{array}$ & 3 & 5 & 5 & $\begin{array}{l}\text { At the first stage of the experiment the } \\
\text { plants were developing better than the } \\
\text { others. At the end of the experiment there } \\
\text { was the speed of the development } \\
\text { reduced }\end{array}$ \\
\hline
\end{tabular}

\section{RESULTS}

The state, use and reproduction of water resources is becoming an increasingly urgent problem in the modern world. Standard watering techniques, including relatively new methods of dripping, intra-soil watering, quickly lead to longterm adverse changes in soils and landscapes (Nazarova, Kurvantaev, 2016 Nazarova, Kurvantaev, 2016). After the end of irrigation, its negative results remain for decades in boharic and rain-fed agriculture (environmental management errors in irrigation lead to the collapse of civilizations of the past and present). Imitating the natural soil moistening, the modern ways of watering give the downward unmanaged mode drenching the soil. As the soil is waterlogged, it results in a superdispersed condition of the finely dispersed phase of the soil (Topunova et al., 2010 Topunova et al., 2010). Then the slicesize soil develops (Prikhodko, Prikhodko 2003, 2003), and the conditions for the development of the rhizosphere of plants and organisms deteriorates dramatically (Rasmussen et al., 1972). The water flotation of aggregates and granulometric elements of the soil takes place, as well as their repackaging. At the drying stage, the soil becomes denser and harder than the original packaging of mechanical elements.

The international program on irrigation and drainage has the considerable impact on overcoming the uncertainty of food production (Role of International..., 2017) is now declared. But at the same time, they do not indicate on what technological platform the prospect of development is seen. 
The simulation frontal gravitational continuum-isotropic paradigm of irrigation and drainage is commonly accepted in the world. For thousands of years it does not change, within its framework technical means simulate the natural combination of the phase of moistening and the phase of water distribution in the soil. In modern irrigation, water consumption is 4-15 times higher than estimated demand (Ochoa et al., 2014). This is unacceptable from the point of view of the preservation of the ecosphere and the economic results of nature management.

The proposals to save water look erroneous, although at first glance attractive, aimed at reducing water supply to plants in the final stage of organogenesis, without changing the method of watering (Banihabib, 2017). The most influential factor is not water saving, but placing the organogenesis of plants in the stress zone. The imperfection of the irrigation technique leads to the formulation of tasks that contradict the nature of soil moistening. The reuse of drainage water exemplifies this assumption (Wahba, 2017). If we keep in mind the strict formulation of the problem of soil moisture, the excess water is only the result of the wrong solution to the problem of water dissipation inside the soil. Изучена подача оросительной воды в размере 100,75, и $50 \%$ относительно расчетной evapotranspiration (Elsayed et al., 2017). But then what is the reliability of the calculation itself, if its data can then be changed twice?

For the period of 2041-2070, it is proposed to use subirrigation to save water (Baule et al., 2017), but the research does not indicate what happens to the soil and plant, how the preferred moisture flows move,

The main hydrophysical characteristics of the soil are considered uncertain (Jarvis et al., 2017). Only sand is able to sustainably reproduce the association between unsaturated water conductivity and soil water potential (Zhuang et al., 2017).

The standard irrigation paradigm does not answer the question of how to avoid the destructive impact of high water content on the soil.

The irrigation development strategy, the water strategy as a whole, should take into account the connections within the system "water - energy - food". Only such an approach would ensure acceptable living conditions and preserve the environment (El Gafy et al., 2017).

In standard irrigation, profile and lateral irregularity of soil moisture is observed (Jangra et al., 2017b Wang et al., 2017). The search for calculation methodology of the statistical uncertainty of the pore space of the dispersed system (Meng, $\mathrm{Li}, 2017$ ) should be taken into account from as this uncertainty is a primordial characteristic of the soil, and the uncertainty increases in the process of its standard moistening, leading to the increases of the uncertainty of the moisture result, which requires measures to overcome the uncertainty of hydrological parameters (Sikorska and Renard, 2017). A new paradigm of soil moistening should be applied as such a hydrological parameter, because the use of this parameter will give a fundamentally new and more definite, hydrological picture of an irrigation object and of a water-producing area in general. Using the method of 3D x-ray microtomography of the real soil elements representing its aggregate structure, we have designed a neuromodel of soil hydraulic conductivity, taking into account the multiple hierarchy of the shape and size of the aggregates forming the structure of soil pore space (Miao et al., 2017).

All this is an additional basis for the application of a new method of soil moistening, which will provide a high degree of certainty of the soil properties during and after moistening, and on a long-term scale.

Fresh water is a global deficit and its conservation requires a radical change in the paradigm of modern irrigation. New water strategy of the world is provided by methods of biogeosystems engineering (Batukaev et al., 2016). It includes the intra-soil pulse continuum-discrete method of soil moistening, based on the principles of thermodynamics of water in the soil. The method controls the supply of water that is dosed discretely and transferred directly into the individual micro-volume to be moistened, which is a discrete microcylinder of primary moisture with a diameter of $2-3 \mathrm{~cm}$, located at a depth of 8-35 cm, bypassing the stage of water transfer through the soil. Then, within 5-10 minutes, the given soil micro-volume, under the action of the potential difference between water and soil, is distributed capillarly in a discrete micro-cylinder of the resulting moisture with a diameter of 4-5 $\mathrm{cm}$ at a depth of $5-45 \mathrm{~cm}$ to a potential of -0.1 to $-0.2 \mathrm{MPa}$, optimal for plant organogenesis (Zaitseva et al., 2013)., 2013). Then, when the soil will come as the humidity of the capillary gap of communication, transport and consumption of water from discrete micro cylinder resulting moisture by distillation of steam.

The contrary circumstances of water transfer in the soil discussed above are overcome by means of the intra-soil pulse continuum-discrete method of soil moistening (Rykhlik, Bezuglova, 2017).

Quantitative data of soil moisture and the state of plants in the experiment arranged by the options are given in Table 1.

During the experiment the plant development begins to differ according to the options. The condition of the plant in the control option was poor.

After standard watering, a short-term water layer is formed on the soil surface. We observed water seepage through the soil in the amount of 30-50\% of the given volume as a result of the formation of preferential flows after the watering for 5 minutes, drainage flow was $10 \mathrm{ml}$, in the next 5 minutes additional $6 \mathrm{ml}$ of water flew from the soil. Preferential water flows are observed even in fairly loose and homogeneous soil structure. In the real conditions of modern irrigation, it should be expected that the contribution of preferential water flows is much greater. With the traditional method of watering, the plants received sufficient moisture, but the agrophysical properties of the soil suffered - an irrigation crust was formed on the surface of the soil, cracks spread inside the soil, the total subsidence of the soil was observed.

With the traditional limited method of watering the plants did not get enough water. The lower limit of wetting after watering was located at a depth of 4-6 cm. In the process of transferring into the soil the water moisten the soil to a state of 
full moisture capacity. Then there is a redistribution of water deep into the soil under the influence of capillary forces, the humidity in the upper soil layer is at the level of minimum water capacity. The discharge of water between the soil blocks of the first order in the form of preferential water flows goes only to the lower boundary of the wetting and, due to the small amount of water, does not reach the bottom of the experimental container. This option confirms that the use of reduced irrigation norms helps to reduce water loss in deep horizons, but a small soil layer is soaked, and the violation of agrophysical properties of the soil surface is intense, water evaporates from the upper $0-5 \mathrm{~cm}$ soil layer.

The picture of the experiment in both options of dripping was almost equal to the two options considered above. The impact of water was only on the part of the surface where the crust is seen.

With an intra-soil pulse discrete method of watering, the soil surface is preserved in the same form as after filling the experimental container with soil. No crust formed. Plants do not develop much better than with the imitation of traditional watering or dripping.

With an intra-soil pulse discrete method of watering, as with the minimum intra-soil pulse discrete method of watering, water is located inside the soil, its distribution after moistening goes without vertical transit, the soil frame is not moistened, which mechanically supports the primary humidification cylinder, water from the primary humidification cylinder spreads to the adjacent volume of soil at a sufficient speed due to the stability of the soil structure. The" memory" of the soil during a short period of time is sufficient to preserve the mechanical framework, since only a small part of the elements of the structure is destroyed in the process of water injection, and then easily restored. Basically, the soil receives water by capillary and film method, which is safe for soil structure. No soil subsidence has been recorded.

A specific feature of the intra-soil pulse continuumdiscrete method of moistening is the peculiarity of water transfer within the soil in a vapor state. We observed the difference of water transfer in the experimental tanks according to the options of water vapor condensation on the transparent walls of the vegetation vessel.

After standard watering the condensation on the container walls on the inner side was plentiful. The droplet size was of 1-3 $\mathrm{mm}$, the location is often almost continuous. Obviously, the amount of water is excessive in terms of the optimal ratio for plants "soil water-soil air". Water moves deep into the soil profile in the form of a stream, because there is an intensive transfer of water to the evaporation surface in the soil. If the water condenses abundantly on the inner walls of the container, it is clear that it easily goes into the atmosphere through the surface of the soil. This explains the unproductive use of water for evaporation. There are some reasons of loss of soil structure due to superdispersed state of the solid phase on the boundary "soil - water flow".

After intra-soil pulse continuum-discrete watering the condensate on the walls of the container from the inner side was formed in a much smaller amount than after standard watering. The size of the drops was $0.2-0.5 \mathrm{~mm}$, the location of drops was clearly separate. In the soil there is no transfer of water in the form of a stream. Water transfer in the form of steam is less intensive, but sufficient to form a concentrated soil solution available to plants. Less water is lost through the soil surface into the atmosphere.

Intra-soil pulse continuum-discrete method of soil moistening delivering water to the individual volumes of soil without vertical water transfer through the soil, and without matching the phases of delivery of water to the soil and its dissipation in a humidified dispersion, gives a fundamentally new opportunities for the preservation of the structure and the composition of the soil. It provides the stability of the moisture conductivity and the main hydrophysical characteristics of the soil, which allows us to formulate a new class of problems of the theory of discrete-continuous transportation in a dispersed system.

These new challenges can be expressed from the following considerations.

The rate of water movement and the stochastic nature of the flow in the disperse system depend on the level and hierarchy of the pore system organization (Vries de et al., 2017). The intra-soil pulse continuum-discrete method of soil moistening is a way to overcome the unfavorable dynamics of the ratio of water supply units in the process of soil moisture, since the phase of transit and excessive wetting of soil aggregates in the humidification zone is excluded.

In addition, it is shown that the evaporation of water and deposition of salts is proportional to the modulus of the water potential in the soil (Shokri et al., 2017). With an intra-soil pulse continuum-discrete method of soil moistening, the water potential in it is lower, therefore, both physical evaporation and transpiration are lower due to a higher than normal concentration of the soil solution and, accordingly, a greater flow of nutrients. The degree of land mass compaction is lower and there is more internal soil surface for the deposition of soluble salts. In addition, the amount of easily soluble salts delivered to the soil with water is several times less because of the lower need for water.

The most important circumstance of the new paradigm of artificial soil moistening is that conditions are created for the priority synthesis of organic matter, optimal interaction of the microbial community of the soil and the mineral phase of the soil, the formation of organic matter (Shein et al., 2016), which under the proposed humidification regime is not destroyed to fractions of granulometric composition. On the contrary, it is possible to establish a trend of improved granulometric composition due to the gradual partial aggregation of the smallest granulometric fractions into relatively larger mechanical organomineral formations (Newcomb et al., 2017), and achieve a stable increase in soil fertility (Van Mansvelt, 2017).

The application of the experimental results to solving the problems of conservation and extended reproduction of the biogeochemical cycle of the ecosphere is possible due to the fact that the studied method of soil moisture has applications in the preservation and expanded reproduction of the 
biogeochemical cycle of the ecosphere, including waste recycling.

The presented materials should be considered in the focus of the synthesis of a promising niche of civilization (Cuomo, 2017; Bohle, 2017), robotization of the technological process of soil moistening as a means of obtaining high economic results, harmonious co-evolution of the ecosphere and technology.

\section{CONCLUSION}

The implementation of the intra-soil pulse continuumdiscrete paradigm of soil moistening in the model experiment confirmed the theoretical assumptions that the new method of humidification eliminates the phase of uncontrolled water seepage, ensures the separation in time of the phase of water supply to the soil and the phase of water dissipation in the soil, sustainable management of water behaviour from the moment of its state as a flow or volume, and until the completion of water dissipation in the capillary and vapor state in the dispersed soil system. It provides water saving, soil preservation and the best conditions for the development of plants.

The intra-soil pulse continuum-discrete paradigm of soil moistening, which is developed within the framework of scientific and technical approach of biogeosystem engineering, is a promising alternative to the existing outdated dangerous for the ecosphere and economic development of civilization simulation frontal gravity continuum-isotropic paradigm of irrigation and drainage. The results of the model experiment can be used to develop a robotic process of soil moistening.

\section{References}

[1] M.E. Banihabib, A. Zahraei, S. Eslamian, "Dynamic Programming Model for the System of a Non-Uniform Deficit Irrigation and a Reservoir", Irrig. and Drain., 2017, vol. 66, pp. 71-81, doi: 10.1002/ird.2055

[2] A.A. Batukaev, V.P. Kalinitchenko, A.A. Zarmaev, A.N. Skovpen, Z.S Dikaev, V.U. Jusupov, et al, "Biogeosystem technique as a base of Sustainable Irrigated Agriculture. Geophysical Research Abstracts”, vol. 18, EGU2016-3416

[3] W. Baule, B. Allred, J. Frankenberger, D. Gamble, J. Andresen, K.M. Gunn, L. Brown, "Northwest Ohio crop yield benefits of water capture and subirrigation based on future climate change projections", Agricultural Water Management, vol. 189, 2017, pp. 87-97, https://doi.org/10.1016/j.agwat.2017.04.019

[4] M. Bohle, Ideal-Type Narratives for Engineering a Human Niche. Geoscience", 2017, vol. 7(1), p. 18, doi:10.3390/geosciences7010018

[5] C.J. Cuomo, Against the Idea of an Anthropocene Epoch: Ethical, Political and Scientific Concerns.

[6] Biogeosystem Technique, 2017, vol. 4(1), pp. 4-8, DOI: 10.13187/bgt.2017.1.4

[7] I. El Gafy, N. Grigg, W. Reagan, "Dynamic Behaviour of the WaterFood-Energy Nexus: Focus on Crop Production and Consumption", Irrig. and Drain., vol. 66, pp. 19-33, doi: 10.1002/ird.2060

[8] S. Elsayed, M. Elhoweity, H.I. Hazem, Y.H. Dewir, H.M. Migdadi, U. Schmidhalter, "Thermal imaging and passive reflectance sensing to estimate the water status and grain yield of wheat under different irrigation regimes", Agricultural Water Management, vol. 189, pp. 98110, 2017, doi:10.1016/j.agwat.2017.05.001
[9] Y. Gao, Y. Yuan, H. Wang, A.R. Schmidt, K. Wang, L.Ye, "Examining the effects of urban agglomeration polders on flood events in Qinhuai River basin China with HEC-HMS model", 2017, Water Science and Technology, vol. 75 (9), pp. 2130-2138, doi: 10.2166/wst.2017.023

[10] E. Gordeeva, "Environmental Policy in a Changing World", International Journal of Environmental Problems, vol. 3(1), pp. 4-12, doi: 10.13187/ijep.2017.1.4

[11] V.I. Glazko, V.G. Sister, "Biogeosystem technique as a method to attenuate the conflict between bio-, agri- and techno- spheres", Theoretical \& Applied Science, vol. 04(36), pp. 46-68. doi:http://dx.doi.org/10.15863/TAS.2016.04.36.9

[12] P. Jangra, R.K. Jhorar, S. Kumar, S.K. Kamra, "Performance Evaluation of a Traveller Irrigation System", Irrig. and Drain., vol. 66, 2017, pp. 173-181, doi: 10.1002/ird.2097

[13] N. Jarvis, J. Koestel, M. Larsbo, "Understanding Preferential Flow in the Vadose Zone: Recent Advances and Future Prospects", Vadose Zone Journal, vol. 15(12), 2016, doi: 10.2136/vzj2016.09.0075

[14] L. Hassan-Esfahani, A. Torres-Rua, A. Jensen, M. Mckee, "Spatial Root Zone Soil Water Content Estimation in Agricultural Lands Using Bayesian-Based Artificial Neural Networks and High- Resolution Visual, NIR, and Thermal Imagery", Irrig. and Drain., vol. 66, pp. 273288, doi: 10.1002/ird.2098

[15] J.D. Mansvelt Van, "Soil Fertility in Agriculture: Russia - Western Europe - USA: in the Past and Today. Biogeosystem Technique", vol. 4(2), pp. 220-231, 2017, doi: 10.13187/bgt.2017.2.220

[16] J. Meng, H. Li, “An efficient stochastic approach for flow in porous media via sparse polynomial chaos expansion constructed by feature selection", Advances in Water Resources, vol. 105, 2017, pp. 13-28. doi:10.1016/j.advwatres.2017.04.019

[17] X. Miao, K.M. Gerke, T.O. Sizonenko, "A new way to parameterize hydraulic conductances of pore elements: A step towards creating porenetworks without pore shape simplifications", Advances in Water Resources, 2017, vol. 105, pp. 162-172. https://doi.org/10.1016/j.advwatres.2017.04.021

[18] S. Nazarova, R. Kurvantaev, "Evolution and prognosis of the development of irrigated soils in the lower part of the Zerafshan valley. Live and biocose systems", vol. 17, 2016, Retrieved from: http://www.jbks.ru/archive/issue-17/article-7

[19] C.J. Newcomb, N.P. Qafoku, J.W. Grate, V.L. Bailey, J.J. De Yoreo, "Developing a molecular picture of soil organic matter-mineral interactions by quantifying organo-mineral binding”, Nat Commun., 2017, vol. 8, p. 396, doi: 10.1038/s41467-017-00407-9

[20] C. Ochoa, S. Guldan, A. Fernald, V. Tidwell, E. Elias, K. Gutierrez., M. Borman, "Surface water and shallow groundwater interactions in semiarid agro-ecosystems of the western USA", Geophysical Research Abstracts, vol. 16, 2014, EGU2014-3161

[21] V.E. Prikhodko, Development of soil in the Volga region under the influence of irrigation, extended abstract on the degree of Doctor of Biological Sciences

[22] W.W. Rasmussen, D.P. Moore, L.A. Alban, "Improvemet of a Solonetzic (Slick Spot) Soil by Deep Plowing, Subsoiling, and Amendments", Soil Science Society of America Journal, vol. 36, 1972, pp. 37-142, doi:10.2136/sssaj 1972.03615995003600010032x

[23] Role of International Research Program for Irrigation and Drainage (IRPID), Irrig. and Drain., vol. 66, 2017, p. 141, doi:10.1002/ird.2120

[24] E.V. Shein, N.V. Verkhovtseva, E.Yu. Milanovsky, A.A. Romanycheva, "Microbiological Modification of Kaolinite and Montmorillonite Surface: Changes in Physical and Chemical Parameters (Model Experiment)", Biogeosystem Technique, vol. 9, pp. 229-234, doi: 10.13187/bgt.2016.9.229

[25] S. Shokri, M. Norouzi Rad, C. Webb, N. Shokri, "Impact of type of salt and ambient conditions on saline water evaporation from porous media", Advances in Water Resources, vol. 105, 2017, pp. 154-161, doi: 10.1016/j.advwatres.2017.05.004

[26] A.E. Sikorska, B.Renard, "Calibrating a hydrological model in stage space to account for rating curve uncertainties: general framework and key challenges". Advances in Water Resources, vol. 105, 2017, pp. 5166, doi:10.1016/j.advwatres.2017.04.011 
[27] I. V. Topunova, V. E. Prikhodko, T. A. Sokolova, "The impact of irrigation on the contents and the mineralogical composition of clay fraction of the chernozems in Rostov region (Bagaevsko-Sadkovskaya Irrigation System)", Bulletin of Moscow University. Series 17: Soil science, vol. 1, pp. 3-10.

[28] I.V. Topunova, V.E. Prikhodko, T.A. Sokolova, "Influence of irrigation on the content and mineralogical composition of the clay fraction of chernozems in the Rostov Region (Bagaevsko-Sadkovskaya irrigation system)", Bulletin of Moscow University. Series 17: Soil Science, vol. 1, 2010, pp. 3-10.

[29] E.T. Vries de, A. Raoof, M.Th. van Genuchten, "Multiscale modelling of dual-porosity porous media; a computational pore-scale study for flow and solute transport", Advances in Water Resources, vol. 105, 2017, pp. 82-95, doi:10.1016/j.advwatres.2017.04.013

[30] M.A.S. Wahba, "Assessment of Options for the Sustainable Use of Agricultural Drainage Water For Irrigation in Egypt by Simulation
Modelling”, Irrig. and Drain., vol. 66, pp. 118-128, doi: 10.1002/ird.2029

[31] T. Wang, T.E. Franz, R. Li, J. You, M.D. Shulski, C. Ray, "Evaluating climate and soil effects on regional soil moisture spatial variability using EOFs", Water Resour. Res., vol. 53, 2017, pp. 4022-4035, doi:10.1002/2017WR020642

[32] R.I. Zaitseva, N.M. Komarov, R.V. Grishina, A.V. Kirichenko, Y.V. Egorov, N.A. Muromtsev, "Resistant varieties of spring barley in the phase of germination - the shoots to soil salinity and moisture deficit during the germination of seeds in solutions. The current state of chernozems", Mat. Int. Conf., September 2013, vol. 24-26, pp. 113-116.

[33] L. Zhuang, C.R. Bezerra Coelho, S.M. Hassanizadeh, M.Th. van Genuchten, "Analysis of the Hysteretic Hydraulic Properties of Unsaturated", Soil. Vadose Zone Journal, 16, 2016, doi: 10.2136/vzj2016.11.0115 